\title{
HPST Framework: Learning About Iran through Historical Inquiry for Students
}

\author{
Jose Pombo, Yuleisy Mena, Sarah A. Mathews \\ Florida International University, United States, Miami, Florida
}

\begin{abstract}
This paper chronicles the use of the Historical, Philosophic, Societal, and Takeaway (HPST) Framework for document analysis within a World History class. This study looks at teacher and student perceptions on the implementation of the HPST Framework with attention to topics that incorporate multiple perspectives and interrogate stereotypes. The study found students could implement all frames of the HPST, however, difficulties were found in their understanding of the philosophical frame. A way to solve these deficiencies was to spend more time discussing how ideology is philosophical found in the other frames such as politics and government systems. After three implementations, a fourth implementation done as a homework assignment using HPST found students also recognized the complexity of human action and of gender roles. Additionally, this article looks at how teachers with limited time or a restricted curriculum can use small excerpts of narrative sources as a learning tool.
\end{abstract}

\section{Introduction}

Although the textbook remains the dominant resource in history classrooms, social studies educators recognize the role that primary source documents play in developing historical thinking [1]. Narratives can serve as a framework for examining historical experience. Roland Barthes defined narrative to be "numberless" expressed through various forms such as written or spoken language, images, and gestures. They are present in every age, place, or society. Nowhere are there a people without them. Moreover, these stories are international, trans-historical, and trans-cultural: it is simply like life itself' [2]. Moreover, Barton and Levstik, using a sociocultural perspective of history, use the term narrative to encompass any form of historical story following marked patterns of causal events, that are chronological, and that include a setting or schema, characters, agent, a goal, and an instrument [3]. As such, narratives predominately encompass aspects dealing with psychological reality and of historiography by way of people, places, and epochs of time. In our experience, students resonate with narratives, and we argue that they should be incorporated into the classroom to motivate and facilitate historical understanding. Narratives give voice to people, places, and events that historical textbooks may silence or not address at all [4]. As Currie reminds us, "narratives are the product of agency; they are the means by which someone communicates a story to someone else" [5].

The Historical, Philosophical, Societal, and Takeaway (HPST) Framework outlines a process whereby students engage in document analysis of complex or controversial issues. Through this framework, information is organized cognitively, allowing for complicated explanations to occur, ultimately culminating with students offering a personal takeaway. This framework works on the assumption that narratives possess historical, philosophical, and socio-cultural components. When students apply this framework to class readings, they should be able to extract content knowledge, engage in higher-order thinking, and discuss implicit and explicit sociocultural aspects within a text. Each of these aspects creates an individual's personal "takeaway" and can serve as an authentic assessment of student learning, meaning it measures students' analytical capacities and goes beyond standardized testing.

\section{Purpose and Objectives}

The purpose of this study was to explore the use of the HPST framework for analyzing narratives and its complexities beyond the textbook. This framework helps students to analyze the interaction of the author, the text, and the reader. Students also draw out historical, philosophical, and socio-cultural frames reflected as complicated conversations. In particular, we examined American students' perceptions of the portrayal of marginalized groups within a context of world history and how these perceptions changed after 
students used the HPST framework to analyze narrative passages.

\section{Theoretical Framework}

The HPST Framework works on two levels aimed at complicating history through conversations about the multiple layers in in each frame and the possible overlap all frames can encounter. The first is the interactive level composed of three interconnected frames or elements. These frames are the author, text, and student reader. Friedrich Schleiermacher referred to the dynamic between these forces as a Hermeneutic Circle [6]. Schleiermacher argued that the key to understanding a text was establishing a real relationship between the reader, text, and context of the reading. Heidegger reinforced this idea by arguing that an author of a text and the text itself cannot be understood separately [7]. Requiring students to conduct preliminary research on an author's personal and professional background, as well as the context in which they were writing, engages students in the Hermeneutic Circle of textual analysis. The second stage of the HPST Framework refers to the analytical level. This level is created by the use and application of four perspectives: the historical, philosophical, societal, and takeaway frames.

The historical frame is based on a critical examination of the "who, what, where, when and how" related to particular events. In other words, students will identify the historical event or phenomena itself; the time, dates, or timeline in which the history occurred; the changes (if any) of this event or phenomena over time; and the geographic location where the historical event transpired. The historical frame recognizes that the interpretative meaning of a text cannot be fully understood unless the reader takes into consideration the circumstances that create the shaping and telling of the historical event itself [8]. This frame incorporates the social, cultural, intellectual, and emotional settings that shaped people's lives and actions in the past [9]. This perspective becomes significant when it is linked to true real-world stories. Wineburg echoed this sentiment by saying that "historical narrative is no longer restricted to great acts of statecraft, but now encompasses everyday acts like childbirth and the daily routines of ordinary people trying to make ends meet" [10].

Within the philosophical frame, teachers will have students explore the belief(s) of a time period, school(s) of thought, public opinion, economic issues, "isms," and the psychological paradigm of the historical event. Students realize that actors are often motivated to act based on personal or organizational attitudes. Analyzing historical events using a philosophical framework helps students identify the philosophical underpinnings the inspired historical behaviors.

The societal frame, includes the social-cultural underpinnings and nuances of this history. Examples of possible topics can include food, religion, traditions, celebrations, enclaves, morals, and values. The sociocultural frame is grounded in Vygotsky's sociocultural theory of understanding [11]. This theory describes learning as "being embedded within social events and occurring as a child interacts with people, objects, and events in the environment" [12]. The societal frame explores constructs in society, including the way constructs like gender and hierarchies are manifested in our world through power or societal norms.

The final frame, the personal takeaway frame, serves as an assessment of student understanding. At this stage, students can communicate connections that they are making between historical, philosophical, and socio-cultural aspects. Weimer suggested that "critical reflection is the highest level of reflection and implies the transformation of a perspective. Many of our actions are governed by a set of beliefs and values that have been almost unconsciously assimilated from our experiences and environment. To undergo a change in perspective requires us to recognize and change these presumptions" [13]. This final frame allows students to truly engage with the text using a hermeneutic circle of conversation between the author, reader, and the text, and displaying their personal take-away when they offer written or oral reflections. This stage also takes into consideration socio-cultural forces that impact the reader. These can include one's encounters with multiple perspectives, one's taken-for-granted assumptions, and one's ability to interrogate generations and stereotypes [14]. In other words, the takeaway provides an opportunity for teachers to examine how students are reading and writing the world [15].

\section{Methodology}

This paper reports the results of a qualitative case study of the application of the HPST framework in one researcher's ninth-grade Advanced Placement (AP) World History class [16]. In particular, the researchers wanted to examine how the students were using the framework to examine historical narratives and if they could use this to disrupt stereotypes or generalizations of marginalized communities. The research questions guiding this project included:

1. How does the implementation of a multidimensional framework of narrative analysis influence students' perspectives of marginalized voices in World History curriculum? 
2. How does the implementation of the HPST Framework produce multifaceted explanations during controversial discussions in the World History classroom (based on immigration, conquest, and cultural xenophobia)?

\section{Context and Participants}

The study took place in a charter school located in the South Florida region of the United States. Hispanic students make up the largest population of students in this region, yet there is also a meaningful population of Haitian and Jamaican students as well. This means that there are a variety of first or second-generation students and English Language Learners. The school in this case study has received multiple awards for academic excellence, placing them as a top school in Florida. The school provides the students with multiple opportunities, including twenty-nine Advanced Placement courses and dual enrollment programs with local universities. In contrast to many affluent schools featuring similar services, eighty percent of the students in this setting are served by free and reduced lunch, a marker of lower socio-economic status in the United States. Ninety-three percent of the population at the school self-identified as Hispanic [17]. All twentyfour students in the class agreed to participate in the study. Ten students were male, and fourteen were female.

\section{Implementing the HPST Framework}

The HPST framework was first implemented into the ninth-grade World History course through the topic of the Iranian Revolution. The teacher-researcher began the lesson by soliciting students' preconceived ideas about the Iranian Revolution, Islam, and gender roles in the Iranian context. Next, she described the HPST framework to the students by explaining each frame and presented the class with excerpts of Marjane Satrapi's 2007 graphic novel The Complete Persepolis [18]. Persepolis is a biographical narrative of Marjane Satrapi and her experiences as a young Iranian woman during its 1979 revolution. As a group, the students identified evidence of the various frames within specific portions of the text. As the takeaway, the teacher-researcher asked the students to write out their perspectives of Islam after reading this autobiography.

The HPST framework was also implemented during two additional class settings throughout the academic year. The second class session focused on the essential question: "Was Columbus a friend or foe of history?" During this session, students were briefly reminded about the framework and then analyzed narratives in small groups. Finally, the third lesson related to the question: "What constitutes a 'legitimate' immigrant?" At this advanced stage, students were asked to locate new narratives and analyze the texts in order to answer the final essential question.

\section{Data Collection and Analysis}

Detailed observations and field notes were collected by the non-participant researcher during each implementation stage; four focused observations were collected overall. These notes captured student responses during verbal discussions. The researchers also collected classroom artifacts to use for document analysis: documents such as excerpts from the graphic novel Persepolis and assignments like the HPST worksheet including all three frames, written exit-slips, which are brief summaries students write up before leaving class, student markups of each narrative, worksheets, and essays. Using qualitative content analysis each researcher coded the observations field notes and written documents independently [19]. Using inductive procedures, the researchers coded the data, identifying common and uncommon emerging themes [20]. Then the researchers compared both sets of codes, narrowing and grouping codes as themes once reaching a consensus.

\section{Results and Discussion}

Data was collected from students by written work, worksheets and classroom artifacts. After coding, several themes emerged. The teacher researcher was able to implement the HPST framework during three in-class session. The HPST framework was implanted in three classroom sessions using narratives that highlighted immigration (i.e. Satrapi's immigration during the Iranian Revolution), conquest (i.e. Christopher Columbus' conquest of the indigenous peoples in the Caribbean) and cultural xenophobia (i.e. the rejection of new immigrant groups or negative stereotypes of Muslims). For the sake of this article we are using evidence from the lesson on Satrapi's Persepolis to demonstrate how students were interacting with the framework and the insights they communicated during the lesson. This section will include the data from that lesson that answers the above stated research questions.

\subsection{How does the implementation of a multi- dimensional framework of narrative analysis influence students' perspectives of marginalized voices in World History curriculum?}

After assessing the framework and using its frames, students acknowledged that there are often multiple 
layers that one should consider when evaluating historical events. The collected data during the three implementations revealed that students recognized the complexity of human action. These reflections pushed students to create multifaceted explanations of the three events.

Take for example data that emerged during the lesson about Persepolis. The intent behind having student readers research the author's background information to include an image was multifaceted: 1) to make a direct connect with the text, 2) to make the reading of the text more relevant, and 3) so that students can understand that an author's background influences his or her writing. In this lesson, the teacher explained that Marjane Satrapi was against the revolution. She was a Shahist who did not side with the coup launched by the Ayatollah Khomeini. At an early age Satrapi immigrated to France with her family and received a Western education. The teacher-researcher explained the author's background which was crucial for students' overall understanding of the text. A student responded by saying that "understanding her background will help because it influences what she writes." After discussing Sharia Law and modesty for women in countries like Iran, which tended to honor more traditional practices, the teacher showed a clip of how fashions changed for Iranian women from the 1920s to the present. The revolution had brought back traditional dress for women which had become more Westernized under the Shah Reza. This was emblematic of and reinforced the philosophical frame since the society wanted an ideological shift towards conservatism seen through the acceptance of Sharia Law and the covering of women through dress. Another student commented that "covering up is stupid." Other students voiced similar perceptions, but many of these changed during the discussion portion of the lesson used by the teacher to implement the TakeAway frame of the HPST Framework.

The teacher commented on the first level - the dynamic between the author, his or her text, and the student reader - that an author has bias and a point of view. The teacher-researcher related to the students that "a text has a voice, and it can speak" to them, but that the author of that text has bias and a point of view that needed to be identified [21]. Finally, she said that using the second level of the framework, or the application of the frames to the actual text, students would be able to extract information from the content.

The students were able to identify excerpts from Persepolis which were exemplary of the historical frame. A student cited the following passage, "In 1979 a revolution took place. It was called the Islamic Revolution." When reflecting on the text, this student continued by saying that "a lot of things changed when the new Shah was elected. This is how the revolution of 1979 started.... that's when everything changed." Multiple students selected the passage, "In 1979 a revolution took place...then came 1980, the year it became obligatory to wear the veil at school." The aforementioned reference made by students not only recognized dates and events within the piece but also the idea of needing a before, during, and after period to conceptualize historical periodization.

The students were able to identify the following excerpts which were exemplary of the philosophical frame (which highlights schools of thought, "ism", and psychological paradigms). The author of this text stated that "we didn't really like to wear the veil, especially since we didn't understand why we had to." A student remarked that "the veil is a philosophic ideal because Sharia Law requires or forces women to hide their upper bodies." Moreover, students were able to recognize the imposition of wearing the veil as a philosophical concept grounded in religious beliefs. A student described that "wearing modernized clothing is highly frowned upon by the Muslim community. The philosophical ideas of girls are changed and other ideologies (such as wearing the veil) are imposed on them." By the end of the exercise they understood how culture values were implemented into law and how this effects the populace. While most students grasped this concept, a few students in the class struggled connecting how a belief system, prompted changes or the preservation of laws, religious practices, and accepted social norms and citizens with different beliefs opposed these same practices in Iran. Students can understand social structure but did not fully grasp the abstract concepts of values and how they seep into cultural traits practiced in everyday life.

Lastly, the students were able to identify the following excerpts which were exemplary of the societal frame (which highlights the nuances of Iranian culture and its people). Satrapi said "why are you wearing punk shoes...but they are (Nike) sneakers...it was obvious that she had no idea what punk was." A student commented during the Take-Away discussion "that when Sharia Law was imposed that there was a change of culture that occurred.... Western Culture was frowned upon by Islamic Culture." The above mentioned was proof that students are extracting content knowledge from the application of frames to the actual text they read. Students used many excerpts from the two previous frames interchangeably such as cultural practices with cultural values because they grasped the complexity of document analysis and categorizing themes within a text.

The Think-Pair-Share activity, which has students think individually, then work with a partner and share, was the physical embodiment of the takeaway frame. This was where the teacher assessed what students had learned. This revealed students' opinions had changed 
after the lesson. A student extrapolated in the TakeAway written paragraph portion of the worksheet that "Islam changed, not everyone was for it. Not everyone has the same ideal and beliefs. Historical, social, and philosophical views can be observed from this." Other students commented that "my views on Islam have altered after hearing Marjane's story because I didn't understand their culture or religion. But I do a little better now. I still feel they have radical Muslims, but I know not all feel or think the same as those like ISIS." A final group stated "our cultures are very much alike until it comes to religion. That's why I think it's wrong to stereotype Islam/Iran as we wouldn't' like it done to us."

\subsection{How does the implementation of the HPST Framework produce multifaceted explanations during controversial discussions (based on immigration, conquest, and cultural xeno- phobia)?}

The collected data revealed that when using the HPST framework students recognized the complexity of gender roles. The lesson that centered on Marjane Satrapi's autobiographical story, as depicted in her graphic novel Persepolis, challenged students' notion of gender roles in Islamic nations. For example, they were shocked that the author embodied a free-thinking, Western woman because she was raised in a traditionalist part of the world, Iran. When they observed an image of the author in class, students responded that "she looks sexy and confident." These students were shocked to see a "Westernized" Muslim woman. This reaction indicates that the image of an uncovered woman smoking a cigarette challenged their stereotype of Muslim women. After encountering this text, many students changed their views about the revolution. They realized that perceptions of one group within a nation are not representative of the entire group. Finally, students identified Satrapi as a dissident and were surprised to see that "women were more militant... they supported the revolution... they had more of a role after Revolution." Additionally, the teacher-researcher found students were displaying geographical context which allows the teacher to infuse geography into the class. Regional bias and regional stereotypes surfaced during the class conversation. The students felt they understood the notion of being a Muslim woman until the teacher challenged these ideas with Marjane's picture. The geographic and gender bias held by students produced multifaceted class discussions by first "meeting" the author in a role not shown in the book or in the students' conceptualization of a Muslim woman, much less any woman in the region known as the Middle East.
The study was effective in creating a relationship between students and the author, having them recognize her as a marginalized voice within the larger context of gender relations. The dominate Western Perspective is that Middle Eastern women are relegated to passive roles in society [22]. The first step in the HPST Framework was to look up the author's biography, including an image, so that students could understand there was a relationship between the author, text, and reader. This was referred to theoretically as a Hermeneutic Circle. Having students inquire about and learn information on the author's background will catalyze a deeper connection to the reading of the text. The inception of the Hermeneutic Circle was evident in this implementation when the teacher asked the students to look up the author and mentioned how she looked Western; in this case the author was smoking a cigarette, smiling, and looking casual. The students know Satrapi is Iranian, but they respond to the image by saying "She looks sexy and confident." The students were inferring about the author's life and making connections even before they were engaged with the text of the graphic novel; by learning about the author, they were already trying to explain what they would find in the text. They made personal connections with the author and achieved the first step in the Hermeneutic Circle. The students in the ThinkPair-Share at the end of class were asked if their thoughts on Islam had changed. Students shared that "I got to see a much harsher lifestyle and how the shift in the leader Ayatollah Khomeini can make such a big impact in someone's life." Students felt compassion for a woman whose stereotype they had pointed out as being a terrorist, based on their preconceptions about Iran, Islam, and what they had previously seen in the media. The Hermeneutic Circle established a relationship between reader and author through biography in narrative. They looked at the individual and how the revolution affected this person rather than a religious group or the entire country.

The students understood that Muslim women, even young girls actively protested the new implementation of wearing the veil, different from the images of support for the revolution and its traditional ideas such as the wearing of the veil, while using the philosophical frame. Students recognized that women were taking a less passive role identifying under the philosophical framework that "They are protesting against an idea that they don't have," meaning that the girls at Marjane's school were unhappy with the new dress code. In the societal framework they wrote that "The different restrictions, like the veil, show that there are problems in the society." They understood Muslim women are not all the same and they themselves had a conflict with their government. The HPST allowed controversial topics such as the wearing of the veil to 
be seen by students as a problem even Muslim women themselves had to tackle at home in Iran.

Students wanted to know more about Satrapi and were interested in her background and point of view and constantly mentioned during the implementation that they "she, Marjane" was feeling one way or another. Moreover, students were able to identify the tone and language in some of the excerpts, explaining that there was a "loss of identity" that young Marjane experienced in the excerpt title "The Veil" based on her facial expression in the graphic novel as well as the few words printed on the excerpt. They empathized with the author once again becoming part of Barthes' Hermeneutic Circle [23].

\section{Universality of the HPST}

The HPST Framework offers a flexible method of teaching history because it can be used in multiple classroom settings or tailored to the needs of specific teachers. Throughout our various implementations, the HPST Framework took on distinct functions and forms. This article has demonstrated how the framework was used to examine narratives about the Iranian Revolution. In particular students recognized the complexity of gender roles and the complexity of human action during historical events. Since then, the framework has been used to cover various themes, as larger concepts for students to grasp, like immigration or revolution, while also serving as an analytical tool for specific document analysis with its historical, philosophical, societal, and takeaway frames.

In the United States, the Advanced Placement classroom is one where students and teachers are pressed for time due to content requirements. The students are required to complete comprehensive tests over the material, and those test then designates whether students receive college credit. In some school districts schools are also rewarded or penalized based on students' pass rates. These constraints leave little room for deviating from the curriculum and engaging in group work. This can be said of most classrooms in today's high stakes testing environment. Teachers must be creative and allow space for new innovative pedagogical strategies and assignments that engage students by teaching beyond the test. Understanding these limitations, the researchers decided to include a new topic to students as a take home assignment to test the flexibility and effectiveness of the framework for independent student work. Our last implementation involved the use of the HPST as a homework assignment to target specific skills and successfully achieved its goal of student identification of historical, philosophical, and societal components of text within a document. For this assignment, we used the topic of
Peter the Great's expansion of Westernization in Russia.

At the time, this AP World History class was covering the themes of enlightened despots, and more specifically Peter the Great's attempts to Westernize Russia. In accordance with the HPST Framework, students learned the context of Peter the Great's life, including his violent childhood and his fascination with technology. Classroom lectures covered his creation of a Russian navy and his upheaval of the old order of Russian politics and societal norms. For homework, the teacher assigned to the class four primary sources related to Peter the Great that she found online. The HPST Framework includes a section where the students would have to look up the author of the excerpts within the narrative. The homework assignment did not include this because the lecture portion of the class already covered this for students. This process allowed the teacher to integrate the elements of the HPST Framework while targeting specific parts of the framework, such as document analysis. Here, the teacher assigned primary documents which are part of the Advanced Placement World History requirements to be interpreted within context. The model of the HPST Framework is then adapted to the needs of the teacher following the AP World History curriculum requiring primary document analysis.

The homework assignment created by the teacherresearcher was a word document containing four primary sources related to Peter the Great which she found online. Trying to expose students to popular symbols and known iconic political cartoons and material culture, she made sure to include the famous picture of Peter the Great cutting of the Beards of the Boyars, Russia's highly influential nobles, who exhibited long robes and long beards, contrary to the European fashions Peter had witnessed while in Europe.

The teacher-researcher asked the students to create a color-coded key for the historical, philosophic, and societal frames. The assignment directed students to highlight with the correct color instances in the documents where they found material relating to each of these frames. Then students were asked to write a paragraph to describe their "take-away" after engaging with the material.

In preparation for the homework assignment, the teacher modeled the home activity so that students could see how to show their work using the different frames. The historical frame was highlighted in yellow, the philosophical frame in blue, and the societal frame in red. The teacher gave these instructions verbally in class and wrote them online as directions for the students to follow. 
Students successfully identified the various frames using the color-coded system the teacher assigned. The students grasped the historical frame, correctly identifying dates, years, and historical concepts like Westernization. The societal frame saw few students struggle, since most understood the frame meaning human relations, practices, and traditions that were part of a culture. They identified the social hierarchies that existed in Russian society and the authority Peter had over the Boyars, Russia's noble ruling class. However, the philosophical frame was understood by students, but the frame needed reinforcement. The teacher reexplain how an ideology seen through value systems is expressed in public opinion, the intelligentsia of a nation, or by the legislative policies created by governmental bodies. After scaffolding, or reexplaining, the students correctly identified the cutting of the beards of the boyars as the physical representation of new ideological shift from tradition to modern Westernization implemented through Peter the Great's reforms.

\section{Significance}

The HPST framework contributes to the literature by prioritizing narratives to convey information through stories which humanize the people involved in significant world events. Narratives allow students to sympathize with the other. The various layers of information portray how multiple groups are affected and the causes of their actions and decisions. HPST takes existing classroom discourse such as discussion about philosophy, politics, and society and power and cognitively arranges it in two levels for students to engage with the text and the author followed by an analytical layer to enhance comprehension and critical thinking.

The HPST is significant for the teaching profession because it expands the arsenal of tools available to educators. It allows students in engage in discovery learning instead of prescribed analysis by the teacher. Students discover the impact of events through narratives that familiarize students with diverse groups in the society.

This framework gives teachers and students a simple tool to unpack the complexities found in a narrative as well as engaging students in controversial topics by dissecting and analyzing scholarly texts. This study found that students understand the different levels of human experience and thought embedded in narrative sources, factors teased out by analyzing historical, philosophical, and societal implications of historical accounts. By engaging controversial topics through an intentionally designed tool, students understood that historical causation exists, various actors within the same event have opposing views, governments do not reflect their people, and stereotypes risk erroneous misconceptions. These findings support the use of the HPST Framework in secondary history courses, especially class sessions that focus on complex ideas exposed through narrative.

\section{References}

[1] Nokes, J.D. (2010). Observing literacy practices in history classrooms. Theory and Research in Theory and Research in Social Education, 38(4), 515-544. doi: 10.1080/00933104.2010.10473438. Nokes, J.D., Dole, J.A., and Hacker, D.J. (2007) Teaching high school students to use heuristics while reading historical texts. Journal of Educational Psychology, 99, 492-504. Shanahan, C., Shanahan, T., and Misischia, C. (2011). Analysis of expert readers in three disciplines: History, mathematics, and chemistry. Journal of Literacy Research. 43(4), 319-351. doi:10.1177/1086296X11422033. Wineburg, S. (1998). Reading Abraham Lincoln: An expert/expert study in the interpretation of historical text. Cognitive Science, 22(3), 319-346.

[2] Barthes, R. (1972). Mythologies. 1957. Annette Lavers (Trans.). New York, NY: Hill and Wang, 302-06.

[3] Barton, K. C., and Levstik, L. S. (2004). Teaching history for the common good. New York, NY: Routledge.

[4] Hilburn, J., and Fitchett, P. (2012). The new gateway, an old paradox: Immigrants and involuntary Americans in North Carolina history textbooks. Theory \& Research in Social Education, 40(1), 35-65.

[5] Currie, G. (2010). Narratives and narrators: A philosophy of stories. Oxford: Oxford University Press, pp. 1.

[6] Redeker, M. (1973). Schleiermacher: Life and Thought. John Wallhausser (Trans.). Philadelphia, PA: Fortress Press.

[7] Heidegger, M. (2002). The Origin of the Work of Art. Julian Young and Kenneth Haynes (Trans.). London: Cambridge University Press.

[8] Dilthey, W. (1976). The development of hermeneutics. In H. Rickman (Ed. and Trans.), W. Dilthey: Selected Writings (pp. 246-263). London: Cambridge University Press.

[9] The Historical Thinking Project. (n.d.). Continuity and change. Retrieved from: http://historicalthinking.ca/ continuity-and-change.

[10] Wineburg, S. (2001). Historical thinking and other unnatural acts. Philadelphia, PA: Temple University Press, pp. 15.

[11] Vygotsky, L. (1986). Thought and Language. Cambridge, MA: The MIT Press. (Original work published 1934). 
[12] Kublin, K.S., et al. (1998). Prelinguistic dynamic assessment: A transactional perspective. In A.M. Wetherby, S.F. Warren, and J. Reichle (Eds.), Transitions in prelinguistic communication (pp. 285-312). Baltimore, MD: Paul H. Brookes, pp. 287.

[13] Weimer, M. (2012, June 26). Four levels of student reflection. Faculty Focus. Retrieved from: https://www.facultyfocus.com/articles/teaching-andlearning/four-levels-of-student-reflection/.

[14] Lewison, Mitzi, Amy Seely Flint, and Katie Van Sluys. "Taking on critical literacy: The journey of newcomers and novices." Language Arts 79, no. 5 (2002): 382-392; Lewison, Mitzi, Christine Leland, and Jerome C. Harste. (2014). Creating critical classrooms: Reading and writing with an edge. New York, NY: Routledge.

[15] Freire, Paulo, and Donaldo Macedo. (1987). Literacy: Reading the word and the world. Westport, CT: Bergin \& Garvey.

[16] Stake, R. (2005). Qualitative case studies. In N.K. Denzin and Y.S. Lincoln (Eds.), The Sage Handbook of Qualitative Research (3rd Ed.) (pp. 443-466). Thousand Oaks, CA: Sage.

[17] Doral Academy Charter High School, CollegeSimply, Retrieved June, 6, 2017, from http://www.collegesimply.com/ k12/school/doral-academycharter-high-school-doral-fl-33172/

[18] Satrapi, M. (2007). The complete Persepolis. New York, NY: Pantheon

[19] Berg, Bruce L. (2004). Methods for the social sciences. Qualitative research methods for the social sciences. Boston: Pearson Education. Gee, J.P. (2004). Discourse analysis: What makes it critical. In R. Rogers (Ed.), An introduction to critical discourse analysis in education (pp. 19-50). Mahwah, NJ: L. Erlbaum Associates.

[20] Patton, Michael Q. (2015). Qualitative research \& evaluation methods: Integrating theory and practice (4th ed.). London: Sage.

[21] Empirical data from this study came from structured classroom observations, worksheets, and exit slips.

[22] Sensoy, Özlem. (2010). "Ickity-ackity open sesame": Learning about the Middle East in images. In Binaya Subedi (Ed.), Critical global perspectives: Rethinking knowledge about global societies (pp. 39-56). Charlotte, NC: Information Age.

[23] Martin, W. (1972). The hermeneutic circle and the art of interpretation. Comparative Literature, 24(2), 97-117. 